\title{
ECCLESIA REFORMATA SEMPER REFORMANDA: REFLEKSI BAGI PEMBAHARUAN GEREJA INJILI
}

\author{
Mulyo Kadarmanto \\ mulyo.kadarmanto@uph.edu
}

\begin{abstract}
This paper aims to discuss the principle of ecclesia reformata semper reformanda which is the fruit of the continuation of reform. Through this research literature study will look at the historical background and principles of the slogan, which is expected to be able to find its relevance for the evangelical church in this global era. With an ongoing commitment to renewal in the evangelical church, the evangelical church can again understand its historicity as a doctrinal movement that places the gospel (the Scriptures) as the main foundation for renewal. Recognizing that continuous renewal is a necessity for the evangelical church, will certainly encourage efforts for the evangelical church to maintain purity and vitality, so as to be able to face the present challenges within the framework of the evangelical doctrine as a doctrinal heritage of reform.
\end{abstract}

Keywords: Semper reformanda, renewal, evangelicalism, reformation, doctrinal inheritance

Abstrak: Tulisan ini bertujuan untuk membahas prinsip ecclesia reformata semper reformanda yang merupakan buah kelanjutan reformasi. Melalui studi literatur penelitian ini akan melihat latar belakang sejarah dan prinsip slogan tersebut, yang diharapkan mampu menemukan relevansinya bagi gereja injili di era global ini. Dengan komitmen pembaharuan yang terus menerus dalam gereja injili, maka gereja injili dapat kembali memahami historisitasnya sebagai gerakan doktrinal yang menempatkan Injil (Kitab Suci) sebagai fondasi utama pembaharuan. Menyadari bahwa pembaharuan yang terus menerus adalah suatu keniscayaan bagi gereja injili, tentunya akan mendorong upaya bagi gereja Injili untuk menjaga kemurnian dan vitalitas, sehingga mampu menghadapi tantangan kekinian dalam kerangka dokrin injili sebagai warisan doktrinal dari reformasi.

Kata Kunci: Semper reformanda, pembaharuan, injili, reformasi, warisan doktrinal

\section{PENDAHULUAN}

Dalam peringatan 500 tahun Reformasi gereja (1517-2017), slogan "Semper Reformanda", bagi saya memiliki ketertarikan tersendiri, yang menguak kembali ingatan akan peristiwa reformasi beberapa abad yang lalu, yang memungkinkan keberadaan gereja untuk menemukan hakikatnya kembali dimasa kini. Gereja Injili sebagai buah dari peristiwa monumental Reformasi, sesungguhnya memiliki hakikat ini, yaitu untuk selalu memperbaharui diri(semper reformanda).

Prinsip semper reformanda adalah hal yang sangat penting dalam gereja injili, seiring dengan seriusnya tantangan dunia postmodern dan global, gerakan (gereja-gereja) injili pada banyak hal mengalami degradasi dalam doktrin yang kemudian telah 
mempengaruhi banyak hal dalam praktek gereja. Lihat saja salah satunya yang masih mendera gerakan injili hingga masa kini, yang masih terjebak dalam doktrin dan praktek dualisme dengan menganggap yang rohani jauh lebih baik, penting dan terutama dari yang jasmani, ${ }^{1}$ akibatnya penginjilan kehilangan penekanan pada dimensi sosial. ${ }^{2}$ Menurut David Bosch ini mengakibatkan minat kaum injili terhadap keprihatinan sosial menjadi semakin tenggelam dan dihapuskan. ${ }^{3}$

"Ecclesia reformata semper reformanda" sebagai satu slogan yang terus disuarakan dalam kekristenan. Slogan ini sendiri dapat diartikan sebagai "the church must always be reforming", seringkali digunakan secara singkat yaitu "semper reformanda" (always reforming)- senantiasa memperbaharui diri. Motto ini merupakan slogan yang lahir dari suatu kelanjutan peristiwa sejarah dalam penemuan kembali hakikat gereja, yaituperistiwaReformasi. Istilah "semper reformanda" pertama kali digagaskan oleh Jodocus van Lodenstein, sekitar tahun 1674. Memang para reformator, khususnya Martin Luther dan Yohanes Calvin tidak menggunakan secara khusus frasa ini, tetapi ini muncul sebagai kelanjutan komitmen melakukan reformasi (pembaharuan) dalam gereja. Kelly M. Kapic menyatakan bahwa:

While prominent Reformers such as *Luther and *Calvin did not use this specific phrase, it accurately reflects the emphasis on continual reform according to Scripture that fueled the Reformation. Like van Lodenstein, Reformed theologians insist that every church in every generation must value the gift of *tradition while submitting to the reforming Spirit who continues to lead God's people to grasp the truth as made known in the normative * revelation of Scripture. ${ }^{4}$

Searah dengan hal itu Jonathan R. Huggins juga menjelaskan bahwa motto itu muncul kemudian setelah Luther dan Calvin, yang muncul dari the Nadere Reformatic movement of the seventeenth-century Dutch Reformed Church. Dimana motto ini kemudian menyebar luas dalam gereja-gereja khususnya yang ada dalam hubungannya dengan tradisi Reformed. ${ }^{5}$

${ }^{1}$ Lih. Paul G. Hiebert dan Monte B. Cox, "Evangelism and Social Responsibility" dalam Evangelical Dictionary of World Missions, A. Scott Moreau (ed) (Grand Rapids, Carlisle : Baker Books, Paternoster Press, 2000), 344.

${ }^{2}$ Robert E. Webber, The Secular Saint : The Role Christian In The Secular World (Grand Rapids : Academie Books, 1979), 175.

3 David J. Bosch, Transformasi Misi Kristen : Sejarah Teologi Misi yang MengubahdanBerubah(Jakarta: BPK GunungMulia, 1997), 489-490.

${ }^{4}$ Kelly M. Kapic, Wesley Vander Lugt, Pocket Dictionary of the Reformed Tradition(InterVarsity Press, 2013), 109.

${ }^{5}$ Jonathan R. Huggins, Living Justification: A Historical-Theological Study of the Reformed Doctrine of Justification in the Writings of John Calvin, Jonathan Edwards, and N. T. Wright (Wipf and Stock Publishers, 2013), 200. 
Dengan melihat prinsip semper reformanda dan juga tantangan gereja injili di era ini, penulisan ini bermaksud untuk membahas tantangan apa yang diperhadapkan kepada gereja injili saat ini dan bagaimana gereja injili telah menyikapinya, yang kemudian akan dilanjutkan dengan membahas hakekat injili sebagai satu gerakan pembaharuan denganberazaskan prinsip semper reformanda. Semoga upaya penulisan ini dapat membuahkan sesuatu yang bermanfaat bagi gereja injili dalam tantangan kekinian.

\section{KONDISI GEREJA INJILI DI ERA POSTMODERNISME}

Dalam bagian ini, akan melihat lebih banyak fenomena gereja injili yang merupakan hasil penelitian dan pengamatan para teolog injili dalam konteks Amerika. Kendati para teolog peneliti melakukan dalam konteks tersebut, namun sesungguhnya banyak hal yang dipaparkan para teolog tersebut juga seperti apa yang terjadi dalam kondisi gereja-gereja injili di Indonesia. Hal ini disebabkan karena perkembangan teologi gereja injili Indonesia lebih berkiblat pada teologi dan perkembangan gereja Injili di Amerika.

Kita harus mengakui bahwa perubahan dan kemajuan zaman sangat signifikan, khususnya dalam perkembangan era digital sebagai hasil dari masa modernisasi dan masa ini seringkali disebut dengan masa postmodernisme. Tantangan terhadap gereja di masa postmodern semakin kuat dan menjelma dalam wujud yang mungkin tidak disadari untuk dideteksi oleh gereja. Dalam era modern, gereja diperhadapkan dengan rasionalisme yang diperjuangkan kaum liberal dalam upaya membongkar dan merekonstruksi ortodoksi kekristenan. Namun, tidak hanya sampai disitu, dalamdunia pascamodern juga memberikan begitu banyak tantanganlanjutan dalam teologi Kristen. Kaum injili yang menerima ide-ide postmodern percaya bahwa teologi Kristen harus meninggalkan sisa-sisa keterikatannya dengan modernisme dan menerima model baru yang lebih sesuai dengan pemikiran postmodern. ${ }^{6}$ Ada yang mengklaim bahwa menekankan Alkitab sebagai wahyu yang proposisional merupakan hal yang bisa dipertanyakan atau bahkan salah, dan berpandangan bahwa pandangan terhadap Alkitab harus dievaluasi kembali, dengan alasan komunitas harus didahulukan daripada proposisi-proposisi doktrin. Dan di sisi lain ada pihak yang mengklaim bahwa teologi harus mengutamakan natur narasi dan bukannya

\footnotetext{
${ }^{6} \mathrm{Hal}$ ini salah satunya merupakan pemikiran dari Stanley J. Grenz, ia mengatakan bahwa "transisi dari era modern kepada era postmodern merupakan tantangan bagi gereja, khususnya dalam gereja menjangkau generasi mendatang. Berhadapan dengan konteks baru ini, kita tidak boleh kembali kepada jebakan modernisme yang melahirkan evangelikalisme (paham injili). Stanley J. Grenz, Pengantar untuk Memahami Posmodernisme \& Peluang Penginjilan Atasnya (Yogyakarta : Andi Offset, 2001), 20.
} 
sistematik abstrak dan konseptual. Penuturan kisah Kristen harus menggantikan penetapan doktrin Kristen. ${ }^{7}$

Dalam pengamatan Ronald J. Sider melihat bahwa gereja Kristen termasuk komunitas injili, tidak sanggup untuk menolak gelombang relativisme, materialisme dan individualisme. Relativisme telah menyerang pemikiran injili. Para pemimpin gereja dan teolog membuat injil-injil murahan tentang kekayaan atau membuat pembenaranpembenaran canggih tentang 'materialisme yang saleh' untuk menyucikan keasyikan kaum injili yang makin meningkat terhadap kelimpahan materi. ${ }^{8}$ Dalam menanggapi perkembangan dunia postmodernyang memiliki kebudayaan menjunjung kebenarankebenaran yang sebenarnya bukan kebenaran. Para pengabdi gereja menyimpulkan bahwa mereka harus mengurangi beban. Artinya sudah waktunya untuk menyingkirkan kerangkakerja kepercayaan tradisionalnya ke latar belakang, menguburkan wawasan dunia tradisional dan meninggalkan konvensi-konvensi yang dulunya menghasilkan kegiatan rutin. Kesimpulannya supaya dapat berkembang dengan pesat dalam dunia baru ini, gereja harus menyamarkan dirinya sendiri. ${ }^{9}$

Bagaimana kondisi gereja dan teologi injili menghadapi tantangan di masa saat ini. Beberapa teolog diantaranya Ronald Sider, Mark A. Noll, David F. Wells, dan Joseph Tong memberikan analisis mereka dalam point-point berikut ini:

Pertama, kaum Injili kurang menghormati warisan akal budi reformasi.

Mark A. Noll menyimpulkan hal tersebut dengan melihat bahwa warisan injili berawal dengan Reformasi dan dilanjutkan dengan gerakan Puritan. Namun sikap kaum injili modern terhadap warisan itu tidak memberikan penghargaan sebagaimana mestinya. Dalam hal ini Mark Noll menjelaskan mengapa rasa hormat terhadap akal budi reformator dan puritanis tidak ada lagi pada kaum injili, yaitu: Pertama, kaum injili merupakan produk revivalisme.Kedua, kaum injili merupakan penerima manfaat dari pemisahan antara gereja dan negara, yang tidak banyak memberikan sumbangsih dalam intelektual. Ketiga, kaum injili adalah pewaris dari sintesis budaya Kristen. Keempat, kaum injili memiliki kebiasaan mental yang dipengaruhi oleh gerakan kaum fundamentalis, yang memelihara esensi kekristenan dan memangkas keyakinan protestan untuk mengasihi Tuhan dengan segenap hati. ${ }^{10}$

\footnotetext{
Douglas

Groothuis,

PudarnyaKebenaran:

MembelaKekristenanTerhadapTantanganPostmodernisme (Surabaya : Momentum, 2003), 103.

${ }^{8}$ Ronald J. Sider, Skandal Hati Nurani Kaum Injili (Surabaya: Perkantas, 2007), 137-138.

${ }^{9}$ Ibid., hlm. 296.

${ }^{10}$ Mark A. Noll, Skandal Pemikiran Injili (Surabaya: Momentum, 2008), 67-68.
} 
Kedua, kaum injili mengabaikan teologi gereja. Dalam penelitian David Wells terhadap teologi dan kehidupan kaum injili di gereja, maka Wells menjabarkan bahwa teologi di gereja mengalami kelenyapan karena diabaikan dan tidak lagi menjadi pusat. Kekosongan dipusat itu digantikan dengan modernitas. Apalagi saat ini identitas kaum injili terpukul telak dengan adanya kaum injili yang menerima modifikasi ortodoksi. Pelayanan Kristen telah menjadi seperti profesi, dan mahasiswa tidak lagi berusaha memperoleh keahlian dalam ilmu teologi. Kemerosotan teologi di tandai dengan penggantian jurusan teologi dengan studi agama dan penggunaan bahasa filosofis. Perkembangan di Eropa dan Amerika menyingkirkan teologi dari universitas dan mengasingkannya dari lingkungan akademis. Hilangnya unsur pengakuan ini merupakan akibat dari kaum injili memiliki identitas yang tidak kuat dan jelas dalam menghadapi modernitas, karena kekuatannya telah terurai dengan banyaknya penggunaan nama injili.Karakter yang muncul dan berdiri kuat pada saat ini adalah individualisme dan kompromi yang mengubah kebijakan dan fungsi teologi, yang bergerak bersamaan modernitas. Reformulasi karakter berjalan bersama reformulasi iman injili. Dimana injili menekankan bahwa Kristus adalah pribadi yang harus dikenal secara pribadi. Ini membawa pada pencarian iman bukan berdasarkan kebenaran Alkitab yang objektif tetapi berdasarkan pengalaman subjektif iman. Mempertahankan ortodoksi dan wawasan doktrinal tidak lagi mendapat tempat dalam kebudayaan dan semakin menghilang dalam gerakan injili, karena semua itu menuntut refleksi dan penilaian. ${ }^{11}$

Ketiga, teisme Kristen diganti dengan idealisme. Modernitas telah menjalar dan merasuk dalam dunia kekristenan serta menyebabkan sebuah kekosongan dalam inti kekristenan. Ikatan tradisi, otoritas dan kekuasaan telah hancur. Modernisasi dan sekularisme telah merampas kekuatan ikatan itu. Hal ini tentunya mengakibatkan teisme Kristen dalam masyarakat barat telah diganti dengan idealisme. Sekarang kekristenan berada dalam peradaban modernitas yang digambarkan oleh Wells seperti katak dimasak dalam panci air yang makin lama tempratur semakin panas dan mematikan katak itu. ${ }^{12}$

Keempat, profesionalisasi fungsi pelayanan. David F. Wells melanjutkan bahwa pengaruh modernitas juga menjadikan gereja memberi daya tarik komersial dan pertumbuhan jenis iman injili juga diakibatkan oleh adanya arus keberpusatan diri yang kuat, yang mengalir di dalam jiwa modern. Pelayanan khotbah bertemakan kebahagiaan dan penerbitan injili meraup keuntungan dengan judul berkenaan dengan diri. Pendeta

\footnotetext{
${ }^{11}$ Ibid., 111-147.

${ }^{12}$ David Wells, Tiada Tempat Bagi Kebenaran (Surabaya: Momentum, 2004), 79-102.
} 
menjadi seorang psikolog yang bertugas memelihara relasi yang baik dan hangat. Hal ini semua mengakibatkan visi injili yang sedang didesak oleh minat kecil dari diri yang menimbang-nimbang kesalehannya sendiri.Profesionalisme kini menjadi sebuah tuntutan di zaman modern. Profesional yang berarti telah menerima pelatihan dan pendidikan dan bersifat intelektual, yang dapat dipakai untuk memperoleh pendapatan dan mencapai citacita. Memberikan rangsangan terhadap terjadinya perubahan posisi pendeta, dimana pasar telah mendominasi pelayanan mereka. Dulu dituntut ketulusan, kepercayaan dan reputasi, kini profesionalisasi dibentuk oleh kompetensi nilai jual dalam bidang masing-masing. Dalam dunia modern para pendeta cenderung membiarkan fungsi profesional membentuk pelayanan, tugas pastoral yang telah diprofesionalisasikan. Para pendeta mendefinisikan pelayanan sebagai produk yang memiliki pasar yang sedang dicari. ${ }^{13}$

Kelima, spiritualitas palsu. David F. Wells juga menjelaskan bahwa dalam banyak pelaksanaan kebaktian saat ini, kaum injili secara tidak sadar mencanangkan fakta bahwa Allah hanya tinggal secara ringan di dalam gereja. Ini terbukti dengan meluasnya spiritualitas Reader's Digest yang saat ini semakin hari menjadi semakin sinonim dengan istilah injili - satu spiritualitas yang ringan bersemangat, sederhana, menyenangkan, akrab dan membesarkan hati. Gereja telah mengadopsi atmosfer pesta meriah, menyajikan yang enak-enak dan berusaha menghindari ketidakenakan. Minggu demi minggu dosa mungkin diakui, tetapi ia tidak banyak dikaitkan dengan sesuatu yang terjadi dalam dunia nyata. Gereja telah mahir membagi-bagikan Band-Aid bagi banyak orang yang terluka. Ia memberi sedikit anjuran yang tidak berbahaya bagi orang - orang yang cemas, kesepian dan tidak punya siapa-siapa. Ia menawarkan teknik-teknik cemerlang untuk mengelola diri secara lebih baik. Kebenarannya adalah terlalu banyak gereja injili yang tidak berada di skala moral yang sama dengan para pelanggar yang mengisi dunia kita. Spiritualitas yang jorok dari kebudayaan pasca modern sedang meredupkan gereja. ${ }^{14}$

Keenam, Analisis kaum injili yang keliru. Mereka menyarankan bahwa kelemahan gereja terletak pada fakta bahwa kegiatan-kegiatan gereja terlalu kuno, musiknya membosankan, program yang terlalu sedikit, masalah lahan parkir dan khotbah yang terlalu kaku. Permasalahan yang dilihat hanya sebatas masalah administrasi atau organisasional, masalah gaya dan kenyamanan. Hal inilah yang muncul dalam zaman pragmatis ini dan juga lebih terobsesi dengan citra daripada substansi. ${ }^{15}$

\footnotetext{
${ }^{13}$ Ibid., 253-275.

${ }^{14}$ Ibid., 299-301.

${ }^{15}$ Ibid., 301-302.
} 
Ketujuh, Pasca modern menghasilkan otoritarianisme yang tidak bertanggung jawab. Pascamodernisme adalah pemberontakan pemikiran manusia melawan otoritarianisme dari rasionalisme. Menentang fondasi humanisme dan merambat ke dalam teologi Kristen dan menjadi tulang punggung dari banyak orang di sekitar teologi dan parafaith. Pandangan ini menjadikan begitu panteistik dan panenteistik dalam hakikat dan menjadikan diri mereka sendiri sebagai Allah, bermegah atas keunggulan dan meninggalkan firman Allah. Filsafat ini bertumbuh dengan subur ada dari gerakan injili yang mengadopsi filsafat ini sebagai pijakan dalam pemikiran sehingga menghasilkan otoritarianisme yang tidak dapat dipertanggungjawabkan. ${ }^{16}$

\section{SEMPER REFORMANDA: SUATU KENISCAYAAN INJILI}

\section{Injil Sebagai dasar Pembaharuan}

Secara hakiki, Injil (euangellion) adalah kabar baik. Kristus adalah Injil keselamatan yang membawa manusia dalam pembaharuan. Karya kematian dan kebangkitan-Nya telah memproklamasikan bahwa pembaharuan telah dilaksanakan-Nya dengan sempurna. Ia memberikan mandat kepada para murid - rasul dan orang percayauntuk memberitakan Injil.

Selainitu, Injil adalah Firman Allah yang tertulis. Dengan merujuk kepada firman Allah (Scripture) para reformator menghendaki suatu pembaharuan dalam gereja di abad pertengahan. Keinginan kembali kepada sumber mula-mula (ad fontes), merupakan upaya para reformator untuk memperbaharui pengajaran dan praktik gereja yang telah menyimpang dari kebenaran Kitab Suci.

Kitab Suci adalah dasar dan sumber pembaharuan. Sola fide dan sola gratia adalah slogan yang didasarkan atas hakekat Injil sebagai Kabar Baik (sola scriptura). Maka secara logis, ketika gereja reformasi menempatkan Sola Scriptura, maka menempatkan esensi Injil sebagaimana mestinya dan ketertundukan kepada Firman Allah. Klooester mengatakan bahwa "The slogan sola Scriptura adequately reflects their desire to be obedient to Scripture alone and to abandon all tradition that conflicted with the Word of God and to confess only what the Word legitimatizes. ${ }^{17}$ Pecahnya peristiwa reformasi, merupakan sebuah perjuangan yang menginginkan agar teologi dan praktik

\footnotetext{
Joseph Tong, "PenilaianKritisTerhadapBeberapaPemikiranTeologiKontemporer di DalamKekristenan”, dalamJurnalTeologiStulos6/2 (September 2007): 168.

${ }^{17}$ Fred H.Klooster, "The Uniqueness of Reformed Theology a Preliminary Attempt at Description" Calvin Theological Journal 14, no. 1 (April 1979): 40. ATLASerials, Religion Collection, EBSCOhost (accessed September 17, 2017).
} 
gereja didasarkan dan bersumber hanya kepada Kitab Suci. Peristiwa Reformasi inilah yang akhirnya menelurkan istilah "Injili" (Evangelische).

Konon secara eksplisit, 'kaum Injili' pertama kali dikenal sejak tahun 1525 , ketika Martin Luther menunjuk orang-orang yang ingin setia hanya pada Injil (Alkitab), dan gereja Katholik pada waktu itu juga, menyebut "orang-orang evangelische" sebagai orang-orang Protestan yang bereaksi terhadap gereja Roma Katholik yang telah mapan. Kaum Injili pada waktu itu belum dikenal secara formal sebagai suatu gerakan evangelikal (injili) seperti sekarang, namun prinsipnya sama, yaitu setia pada Alkitab dan hanya oleh iman yang diberitakan Alkitab yang tidak pernah diubah. Pada waktu tersebut, di Eropa, yang dimaksudkan dengan gereja 'injili' adalah gereja yang ada khotbah Alkitabnya, karena gereja jenis lain hanya membaca saja. ${ }^{18}$

Ecclesia reformata semper reformanda secundum Verbum Dei, menempatkan bahwa Kitab suci adalah dasar dari segala pembaharuan yang ada. Jonathan R. Huggins menyatakan bahwa, "It refers to the belief that the church must always be subject to Scripture, and remain open to continued reformation in doctrine and life in the light of Scripture. ${ }^{19}$ Dalam terang Kitab Suci, karya Reformasi terus dilanjutkan bagi pembaharuan doktrinal dan kehidupan. Pembaharuan didasarkan atas Prinsip Sola Scriptura dan tota Scriptura sebagai jantung dari gereja Reformasi. ${ }^{20}$ Kedua prinsip ini menempatkan Kitab Suci sebagai dasar pembaharuan, yang membangun pengajaran atas dasar pengajaran seluruh Kitab Suci.

\section{Injili sebagai buah pembaharuan}

Dalam hal ini, sangat penting untuk kembali melihat catatan historis dari akarakar gerakan Injili. Pada awal mulanya, gerakan injili merupakan buah dari pembaharuan yang dilakukan dalam gerakan reformasi di tahun 1517. Dengan dilatarbelakangi kondisi gereja yang berada dalam kondisi yang 'sekarat'. Alister McGrath menjabarkan bahwa dari sistem kegerejaan, kepemimpin, hingga teologi dan praktik gereja. Gereja menjadi lembaga yang diincar setiap orang atau pemimpin dengan menatap penuh nafsu akan kekuasaan, pengaruh dan uang. Teologi dan praktik gereja sangat menyimpang dari kebenaran firman Allah yang seharusnya menjadi fondasi dan sumber dalam teologi dan praktik gereja. Tata gereja yang resmi membutuhkan pembongkaran menyeluruh dan birokrasi kerajaan telah menjadi sangat tidak efisien dan korup. Moral para rohaniwan

\footnotetext{
${ }^{18}$ TogardoSiburian, KaumInjili di antaraFundamentalismedanEkumenisme (Bandung: tidakterbit, 2007), 13-30. Lihat juga dalamhttps://www.britannica.com/topic/Evangelical-church-Protestantism

${ }^{19}$ Jonathan R. Huggins, Living Justification: A Historical-Theological Study of the Reformed Doctrine of Justification, 200. 43.

${ }^{20}$ Fred H. Klooster, "The Uniqueness of Reformed Theology a Preliminary Attempt at Description,
} 
sering tampak lemah dan menjadi sumber skandal jemaat. Bagi banyak orang pada masa itu, jeritan pembaruan merupakan permohonan untuk reformasi gereja dalam bidang administratif, moral dan hukum. Penyalahgunaan dan immoralitas harus disingkirkan, administrasi gereja harus dibersihkan dari korupsi. Dan yang menjadi kebutuhan yang paling mendesak adalah yang berkenaan dengan masalah kerohanian gereja. Kebutuhan itu adalah untuk menangkap kembali vitalitas dan kesegaran iman Kristen. ${ }^{21}$

Alister McGrath melanjutkanbahwa bagi pengamat dan teolog yang kritis seperti Martin Luther dan Yohanes Calvin gereja telah kehilangan visi mengenai warisan intelektualnya. Pada masa reformasi slogan ad fontesdidengungkan, sebagai upaya kerinduan untuk kembali ke sumber-sumber asli, kemelaratan dari periode abad pertengahan dilewati supaya memperoleh kembali kegemilangan-kegemilangan intelektual dan artistis dari periode klasik. Slogan ad fontes berarti kembali ke dokumen-dokumen yang sah dari kekristenan yaitu penulis-penulis patristis dan yang paling utama adalah Alkitab. $^{22}$

Semenjak masa reformasi, jika kita menelusuri tahun-tahun dan abad-abad selanjutnya, maka kita dapat menemukan gereja yang terus diperbaharui. Dimana munculnya Pietisme dan Puritan yang menjadi masa revival bagi umat Allah. Setelah masa-masa kerohanian dan orang percaya mulai kendor, mulai mengalami stagnasi dalam pertumbuhan iman maka diperlukan sesuatu yang baru untuk memperbaharui diri dan gereja supaya dapat kembali bangkit dan mengalami pertumbuhan iman yang progresif. Dapat terlihat dari Pietisme dan Puritan, bagaimana kedua gerakan ini mampu membangkitkan spirit gereja Tuhan dalam melaksanakan misi dan penginjilan keseluruh dunia, yang memberikan dampak dan kebangunan rohani mendunia sebagai pelaksanaan amanat agung Yesus Kristus. Dalam bagian ini secara singkat kita akan melihat dua peristiwa revival setelah Reformasi tahun 1517, yang menjadi momentum kebangunan rohani (pembaharuan) dalam kekristenan yang juga menjadi bagian historis latar belakang gerakan injili di masa kini yaitu Pietisme dan Puritanisme.

Pertama, Pietisme. Sekitar tahun 1677 di Darmstadt, istilah Pietisme muncul dan menjadi populer dikalangan gereja - gereja Lutheran. Ini digunakan sebagai ejekan terhadap kelompok orang yang hidup saleh (Collegia Pietatis), tetapi mereka bukanlah orang dan kelompok yang terlalu eksklusif. Kelompok ini pertama kali didirikan oleh

\footnotetext{
${ }^{21}$ Alister McGrath, Sejarah Pemikiran Reformasi (Jakarta : BPK Gunung Mulia, 1999), 2-5.

${ }^{22}$ Alister E. McGrath, Sejarah Pemikiran Reformasi, 57.
} 
Spener tahun 1669, dengan tujuan memberi arti dan memberikan manfaat kehidupan orang-orang Kristen. Prakarsa ini muncul melihat kebutuhan yang mendesak pada zaman itu. Dimana kemelaratan melanda masyarakat, gereja-gereja sangat bergantung pada raja, dan standar kehidupan pendeta sangat rendah yang mengakibatkan mereka bersedia diperalat pemerintah dan menggunakan mimbar sebagai penyampai peraturan dan keputusan pemerintah. Dalam kondisi inilah pietisme muncul sebagai perwujudan suatu usaha untuk memperbaiki keadaan masyarakat dan gereja. Leonard Hale menyimpulkan bahwa "Singkatnya Pietisme adalah sebuah koreksi atau reaksi, yang berusaha keras mengisi sebuah kekosongan di dalam kehidupan jemaat.",23

Berdasarkan pembagian yang dikutip Leonard Hale dari E.W. Gerdes dalam "Theological Tenets of Pietism, maka ada beberapa karakteristik dari pietisme, yaitu: Pertama, Natura Pietatis yang menekankan manusia baru atau regenerasi (lahir baru) dan menekankan hubungan pribadi dengan Tuhan dan pemberitaan Injil (mission). Kedua, Collegia Pietatismerupakan sebuah persekutuan yang menjalankan kesalehan. Manusia baru bukanlah manusia yang terpisah dari persekutuan dan di dalam hubungan pribadi antar setiap individu dengan Allah dapat ditemukan hakikat kekristenan (Fellowship). Ketiga, Praksis Pietatis menegaskan bahwa teologi tidak pertama-tama menyangkut tuntutan atau ajaran tentang Allah tetapi menekankan pengetahuan tentang bagaimana hidup untuk Allah. Keempat, Reformatio Pietatis, menurut kaum pietis reformasi pertama oleh Luther belum selesai, sebab tidak menyangkut segala bidang kehidupan, karena itu perlu reformasi yang kedua yaitu pembaharuan kehidupan (reformatio pietatis). ${ }^{24}$

Kedua, Puritanisme. Puritanisme diawali di Inggris dan merupakan gerakan yang melakukan reformasi di gereja Inggris. Puritanisme ini seringkali dikenal dengan gerakan revival. Mereka melakukan pembaharuan terhadap ibadah dan memberikan penekanan kepada kemurnian ibadah. Mereka tidak mencari tanda-tanda dan mujizat tetapi tentang kebangunan kembali gereja Tuhan, seperti yang dikatakan oleh Errol Hulse bahwa, "The puritans did not seek a new age of wonders, sign and miracles. Thier was that a church rises or falls as the ministry of the Word rises or falls in that church". ${ }^{25}$ Gerakan Puritan melakukan pembaharuan dalam gereja dan membawa gereja untuk kembali pada kebenaran Alkitab. Puritan membangunkan kembali ibadah gereja yang kosong, memberikan kesegaran dan kemurnian dalam iman kekristenan.Dalam gerakan ini sangat

\footnotetext{
${ }^{23}$ Leonard Hale, Jujur Terhadap Pietisme : Menilai Kembali Reputasi Pietisme Dalam Gereja gereja Indonesia (Jakarta : BPK Gunung Mulia, 1994), 4-11.

${ }^{24}$ Ibid., hlm. 12-17.

${ }^{25}$ Errol Hulse, Who Are The Puritans? (England : Evangelical Press, 2000), 60.
} 
bercorak dengan khotbah yang menekankan pertobatan, kesalehan dan ketaatan kepada Kitab Suci. Mark A. Noll mengatakan bahwa :

"Puritanism might mean strong preaching for conversion, the search for personal godliness and a devotion to lay study of Scripture, but it also seemed to entail less edifying consequences : "enthusiasm", where especially the lower orders pretended to hear teh voice of God in their own ears; antinomianism, where private religious inspiration excused people from observing ordinary laws, morality and reasonable public duties; reverse intolerance, where 'the saints' persecuted their enemies as vigorously as they had been persecuted themselves". ${ }^{26}$

Dengan demikian secara historis nyatalah bahwa sesungguhnya gerakan injili (gereja-gereja injili) merupakan buah Reformasi yang dilanjutkan dengan peristiwa kebangunan lainnya. Secararingkas, TogardoSiburian tuliskan bahwa:

Gerakan evangelikal (injili) berakar pada peristiwa reformasi. Bahkan gerakan evangelikal pada saat ini adalah kelanjutan dari gerakan reformasi melalui Great EvangelicalAwakening dari kebangunan rohani pietis dan puritan (abad 17-18) dan Evangelical Alliance (1854). Kurang dari seratus tahun kemudian didirikan wadah internasional lain yang dinamakan World Evangelical Fellowship (WEF) tahun (1951). Dari asosiasi inilah muncul persekutuanpersekutuan regional dan nasional, termasuk Indonesia (PII 1971). ${ }^{27}$

\section{Pembaharuan adalah Keniscayaan Injili}

Ketiga peristiwa historis yang telah kita lihat (Reformasi, Pietisme, dan Puritanisme) menunjukkan bagaimana, kaum injili terus mengalami pembaharuan. Dengan prinsip ecclesia reformata semper reformanda est secundum Verbum Deimenekankan bahwa pembaharuan adalah penanda identitas yang esensial dari gereja injili. ${ }^{28}$ Dengan klaim prinsip ini gereja injili memiliki posisi bahwa gereja harus terus menerus menguji dirinya sendiri, mempertimbangkan kembali doktrin-doktrinnya dan siap untuk menerima pembaharuan, agar selaras dengan keyakinan ortodoksi kekristenan yang dinyatakan dalam Kitab Suci. ${ }^{29}$

Pembaharuan sebagai satu keniscayaan gereja injili didasarkan atas dasar prinsip keyakinan injili sendiri. A.T.B. McGowan memberikan setidaknya empat alasan mengapa gereja harus selalu memperbaharui dirinya, yaitu: Pertama, Allah berbicara pada hari ini. Jika kita meyakini bahwa Allah hidup dan berbicara pada hari ini, kemudian kita

\footnotetext{
${ }^{26}$ Mark A. Noll, The Rise of Evangelicalism : The Age of Edwards, Whitefield and the Wesleys (Downers Grove: InterVarsity Press, 2003),55.

${ }^{27}$ TogardoSiburian, KaumInjili di antaraFundamentalismedanEkumenisme, 30.

${ }^{28}$ Jonathan R. Huggins, Living Justification: A Historical-Theological Study of the Reformed Doctrine of Justification, 201.

${ }^{29}$ Paul Haffner, Mystery of the Church (Leominster: Gracewing, 2014), 117.
} 
harus juga selalu untuk mendengarkan-Nya dan mereformasi diri. Allah terus berbicara melalui Roh-Nya, melalui firman-Nya. Jika kita mempercayai hal ini, maka kita akan terus menyelidiki Kitab Suci dan kehendak-Nya, di dalam teologi kita, memahami apa yang kita pelajari.Kedua, Teolog dapat mungkin mengalami kesalahan. Teologi dirumuskan oleh keberadaan manusia, dimana keberadaan manusia sangat mungkin mengalami kesalahan. Paul Haffner mengatakan "This expression is also inadequate to express the existence of sinful members of the church, because it fails to consider the Church as essentially holly." ${ }^{30}$ Ketiga, isu-isu baru membutuhkan pemikiran baru.Setiap zaman atau masa memiliki tantangan-tantangannya sendiri,

Sehingga teologi perlu di reformulasi kembali untuk dapat menjadi relevan dalam menjawab kebutuhan tiap-tiap zaman.Keempat, Kitab Suci harus memiliki otoritas atas pengakuan-pengakuan. Salah satu cara agar kita bisa 'selalu melakukan reformasi' adalah dengan meninjau dan menulis ulang pengakuan kita. Hari ini, kita membutuhkan pengakuan (konfesi) baru yang akan berpegang pada penegasan teologis sentral dari pengakuan lama namun akan menerapkan teologi tersebut pada isu-isu masa kini. ${ }^{31}$

\section{REFLEKSI BAGI PEMBAHARUAN GEREJA INJILI}

Memahami historitas injili sebagai gerakan doktrinal warisan reformasi adalah sesuatu yang sangat penting bagi gereja injili, untukdapat tetap berpegang kepada warisan intelektual injili dan berteologi dalam dasar dan prinsip reformasi, serta mempertahankan ortodoksi kekristenan. Dengan tetap memandang zaman ini untuk dapat merefleksikan teologinya dalam konteks kekinian. Dasar dan prinsip berteologi ini penting agar dalam doing theology kaum injili tidak kehilangan arah, namun tetap berfondasi dalam kebenaran. Tanpa merefleksikannya, maka kaum injili hanya akan berteologi dalam ruang kosong yang tidak ada gunanya. Dengan prinsip ini kaum injili akan menemukan kembali kesegaran, kemurnian dan vitalitasnya dalam menghadapi tantangan zaman ini.

Pentingnya keterbukaan dan keterlibatan kaum injili Indonesia dalam melihat dan mengikuti perkembangan injili di dunia saat ini. Mengikuti perkembangan gerakan Injili, untuk dapat belajar banyak tentang isu-isu terkini, sehingga dapat mempelajarinya dan menarik aplikasi, implikasi ataupun relevansinya dalam konteks Indonesia. Untuk itu kaum injili Indonesia juga penting untuk mengalami reformasi diri dan iman, untuk berdiri

\footnotetext{
${ }^{30}$ Ibid., 117.

${ }^{31}$ A.T.B. McGowan, Always Reforming: Explorations in Systematic Theology (Illinois: IVP Academic, 2006), 15-16.
} 
sebagai injili sejati. Selanjutnya kaum injili Indonesia juga harus lebih memotivasi diri dalam mengembangkan kemampuan dalam berbagai bidang agar dapat bergerak secara lebih leluasa dan meresponi perkembangan zaman dan mampu menyikapinya secara alkitabiah.

Mandat kaum injili adalah mandat peradaban, yang mencakup seluruh bidang kehidupan. Injil terbuka secara global, untuk semua orang tanpa dibatasi oleh batasanbatasan tertentu, karena semua orang diberikan kesempatan untuk mendengarkan firman Tuhan. Mandat kaum injili dalam peradaban adalah untuk memanusiakan manusia, yang membutuhkan keselamatan pribadi dan juga pembebasan atau perhatian dalam sosial, budaya, ekonomi dan bidang-bidang lainnya.

Kebangunan kembali yang dibutuhkan saat ini dalam tubuh kaum injili bukan hanya sekedar kebangunan kerohanian, tetapi juga perlu memurnikan gereja itu sendiri dalam segala tujuan, teknik atau strategi untuk mendapatkan pemahaman yang benar tentang hakekat gereja. Gereja yang telah korup dengan gemerlapnya masa pascamodern dan tenggelam dalam kegemilangan yang membawa dalam kegelapan, akan memperoleh kembali hakekatnya sebagai gereja injili yang menempatkan Kitab Suci sebagai otoritas tertinggi dalam teologi dan praktek gereja.

Pengetahuan dan intelektual yang benar tentunya hanya ditemukan dalam kebenaran firman Allah. Kembali kepada sumber-sumber kebenaran merupakan kunci dalam setiap reformasi dan kebangunan rohani yang terjadi dalam catatan sejarah. Kaum injili tidak boleh berkompromi dengan kegemerlapan dunia pascamodern yang memberikan "iming-iming" berbagai ilmu dan filsafat yang menurutnya bisa diterapkan dalam gereja sehingga berusaha untuk mengubah kebenaran yang telah diaffirmasikan. Wells mengingatkan kaum injili untuk melepaskan diri dari keasyikan subyektif dari budaya modern dan mengisi diri dengan minat alkitabiah yang objektif. Tanpa transformasi ini, maka cara pikir dan metode untuk mengembangkan minat alkitabiah akan gagal dan mati. Yang dibutuhkan kaum injili dalam menentang arus modern adalah pemulihan kekuatan dan jalan untuk menuju pemulihan itu adalah semper reformanda. Agar teologi Kristen bisa memegang dasarnya dan maju di dalam mengkonfrontasi tantangan-tantangan pascamodern, ia harus secara jelas dan kuat menegaskan kebenaran proposisional Alkitab yang diilhamkan Allah dan kemampuan Alkitab untuk diketahui secara rasional. ${ }^{32}$ Louis Berkhof menegaskanbahwa:

\footnotetext{
${ }^{32}$ Douglas Groothuis, PudarnyaKebenaran, 132.
} 
"Gereja tidak dapat hanya merasa puas dengan pengetahuan kebenaran Ilahi yang telah diperolehnya dan yang telah diformulasikannya dalam pengakuan iman. Gereja harus menggali lebih dalam segala kekayaan Alkitab supaya harta yang tersembunyi itu dapat diungkapkan sebanyak-banyaknya. Melalui suatu studi ilmiah, gereja harus mencari pengetahuan yang lebih dalam, sebuah pemahaman yang lebih baik tentang firman kehidupan. Gereja berhutang pada kebenaran itu sendiri sebagai wahyu Allah, dan juga berhutang suatu persiapan bagi pelayanan untuk masa-masa selanjutnya. Gereja bertugas menyediakan, atau paling tidak mengawasi, latihan bagi para pengajar dan pendeta untuk masa-masa selanjutnya. ${ }^{33}$

Dengan pengembangan teologi gereja injili, tentunya permasalahan dualisme seperti yang diungkapkan dibagian awal penulisan ini dapat terjembatani dan terselesaikan dalam doktrin injili yang alkitabiah sehingga peran gereja injili akan semakin nyata dalam tantangan dan konsekuensi dunia digital-global. Ada banyak isu yang tentunya diperhadapkan kepada gereja-gereja injili, diantaranya: Isu budaya (LGBT), isu ekologi (pemanasan global), isu ekonomi (Masyarakat Ekonomi ASEAN), isu sosial (kemiskinan), isu teknologi (tantangan era digital-media sosial), Isu pendidikan (anak-anak putus sekolah), isu kebangsaan (tantangan nasionalisme dan pluralitas), serta beragam isu-isu lainnya yang diperhadapkan kepada gereja injili. Artinya dalam kondisi tantangan saat ini, sesungguhnya gereja bukan hanya berpikir dan mengupayakan dengan berbagai cara bagaimana "menggendutkan" kuantitas jemaat, namun menjadi gereja injili yang mampu menjawab secara teologis dan praktis tantangan-tantangan yang langsung diperhadapkan kepada gereja (wargagereja).

\section{PENUTUP}

Dengan demikian pada dasarnya pembaharuan adalah suatu keniscayaan dalam gereja injili. Gereja tidak dapat terus berada dalam status quo, dan pembaharuan bukanlah berarti mengabaikan dan meninggalkan akar-akar historisnya. Dengan melihat akar historis, gereja injili menerima suatu tugas estafet, untuk melanjutkan dan memperjuangkan prinsip semper reformanda. Gereja injili tidak dapat untuk cukup berpuas diri dengan doktrin yang telah ada dan kemudian kurang mengupayakan korelasi dan relevansinya untuk pergumulan dalam konteks kekinian. Otoritas Kitab Suci sebagai dasar dan komitmen gereja Injili adalah final, sesuai prinsip Sola Scriptura. Namun, gereja injili juga perlu untuk selalu melihat tradisi warisan teologi untuk dapat merumuskan terus

${ }^{33}$ Louis Berkhof,TeologiSistematika 5: DoktrinGereja (Surabaya: Lembaga Reformed Injili Indonesia, 1997), 88. 
menerus teologinya untuk menjawab tantangan zaman. Bukan melucuti keunikan doktrinal sebagai gereja injili, namun seharusnya mempertegas dan selalu mereformulasikannya dalam menjawab isu-isu yang berkembang dan diperhadapkan kepada gereja dan warganya. 
Berkhof, Louis, 1997

Bosch, David J., 1997

Grenz, Stanley J., 2001

Groothuis, Douglas, 2003

Haffner, Paul, 2014

Hale, Leonard, 1994

Huggins, Jonathan R.,

Teologi Sistematika 5: Doktrin Gereja. Surabaya: Lembaga Reformed Injili Indonesia

Transformasi Misi Kristen : Sejarah Teologi Misi yang Mengubah dan Berubah. Jakarta: BPK Gunung Mulia

Pengantar untuk Memahami Posmodernisme \& Peluang Penginjilan Atasnya. Yogyakarta : Andi Offset

Pudarnya Kebenaran: Membela Kekristenan Terhadap Tantangan Postmodernisme. Surabaya : Momentum

Mystery of the Church, Leominster: Gracewing

Jujur Terhadap Pietisme : Menilai Kembali Reputasi Pietisme Dalam Gereja - gereja Indonesia, Jakarta : BPK Gunung Mulia 2013

Living Justification: A Historical-Theological Study of the Reformed Doctrine of Justification in the Writings of John Calvin, Jonathan Edwards, and N. T. Wright, Wipf and Stock Publishers

Hulse, Errol, 2000

Who Are The Puritans? England : Evangelical Press

Kapic, Kelly M., Wesley Vander Lugt,

$2013 \quad$ Pocket Dictionary of the Reformed Tradition. InterVarsity Press

McGowan, A.T.B., 2006

Always Reforming: Explorations in Systematic Theology. Illinois: IVP Academic

McGrath, Alister E., 1999

Sejarah Pemikiran Reformasi. Jakarta : BPK Gunung Mulia

Moreau, A. Scott (ed)., 2000

Evangelical Dictionary of World Missions. Grand Rapids, Carlisle: Baker Books, Paternoster Press

Noll, Mark A. 2008

Skandal Pemikiran Injili. Surabaya: Momentum

2003

Siburian, Togardo, 2007

Sider, Ronald J., 2007

Tong, Joseph, 2007

The Rise of Evangelicalism: The Age of Edwards, Whitefield and the Wesleys. Downers Grove: InterVarsity Press

Kaum Injili di antara Fundamentalisme dan Ekumenisme, Bandung Skandal Hati Nurani Kaum Injili, Surabaya: Perkantas

"Penilaian Kritis Terhadap Beberapa Pemikiran Teologi Kontemporer di Dalam Kekristenan", dalam Jurnal Teologi Stulos $6 / 2$

Webber,Robert E., 1979

The Secular Saint : The Role Christian In The Secular World. Grand Rapids : Academie Books 
Wells, David F., 2004

Tiada Tempat Bagi Kebenaran. Surabaya: Momentum

\section{PUSTAKA ONLINE}

https://www.britannica.com/topic/Evangelical-church-Protestantism

Klooster, Fred H. "The uniqueness of reformed theology a preliminary attempt at description." Calvin Theological Journal 14, no. 1 (April 1979): 40. ATLASerials, Religion Collection, EBSCOhost (accessed September 17, 2017).

Lotz, David W. 1981. "Sola scriptura: Luther on biblical authority." Interpretation 35, no. 3: 258-273. ATLASerials, Religion Collection, EBSCOhost (accessed September 7, 2017). 